\title{
HPV testing for cervical cancer screening appears more cost-effective than Papanicolau cytology in Mexico
}

\author{
Yvonne N. Flores • David M. Bishai • Attila Lörincz • Keerti V. Shah • \\ Eduardo Lazcano-Ponce • Mauricio Hernández • Víctor Granados-García • \\ Ruth Pérez • Jorge Salmerón
}

Received: 12 March 2010/Accepted: 10 November 2010/Published online: 18 December 2010

(C) The Author(s) 2010. This article is published with open access at Springerlink.com

\begin{abstract}
Objective To determine the incremental costs and effects of different HPV testing strategies, when compared to Papanicolau cytology (Pap), for cervical cancer screening in Mexico.

Methods A cost-effectiveness analysis (CEA) examined the specific costs and health outcomes associated with (1) no screening; (2) only the Pap test; (3) only self-administered HPV; (4) only clinician administered HPV; and (5) clinician administered HPV plus the Pap test. The costs of self- and clinician-HPV testing, as well as with the Pap test, were identified and quantified. Costs were reported in 2008 US dollars. The health outcome associated with these screening strategies was defined as the number of highgrade cervical intraepithelial neoplasia or cervical cancer cases detected. This CEA was performed using the
\end{abstract}

Y. N. Flores $(\varangle) \cdot$ J. Salmerón

Unidad de Investigación Epidemiológica y en Servicios de

Salud, Instituto Mexicano del Seguro Social,

Av. Plan de Ayala Esq. Central S/N, Cuernavaca,

C.P. 62450 Morelos, México

e-mail: yflores@jhsph.edu

D. M. Bishai

Department of Population, Family, and Reproductive Health, Johns Hopkins University, Bloomberg School of Public Health, Baltimore, MD, USA

A. Lörincz

Wolfson Institute of Preventive Medicine, Barts and The London School of Medicine, Queen Mary University of London,

London, UK

K. V. Shah

Department of Molecular Microbiology and Immunology, Johns Hopkins University, Bloomberg School of Public Health,

Baltimore, MD, USA perspective of the Mexican Institute of Social Security (IMSS) in Morelos, Mexico.

Results Screening women between the ages of 30-80 for cervical cancer using clinical-HPV testing or the combination of clinical-HPV testing, and the Pap is always more cost-effective than using the Pap test alone.

Conclusions This CEA indicates that HPV testing could be a cost-effective screening alternative for a large health delivery organization such as IMSS. These results may help policy-makers implement HPV testing as part of the IMSS cervical cancer screening program.

Keywords Cost-effectiveness - Cervical cancer HPV . Screening · Mexico

\author{
E. Lazcano-Ponce \\ Centro de Investigación en Salud Poblacional, Instituto Nacional \\ de Salud Pública, Cuernavaca, Morelos, México \\ M. Hernández \\ Secretaria \\ de Prevención y Promoción de la Salud, Secretaría de Salud, \\ México D.F., México \\ V. Granados-García \\ Unidad de Investigación en Economía de la Salud, Instituto \\ Mexicano del Seguro Social, 3er piso. Ed. de las Monjas. Av. \\ Cuauhtemoc 330. Colonia Doctores, C.P. 06720 México D.F., \\ México \\ e-mail: victor.granados@imss.gob.mx \\ R. Pérez \\ Departamento de Abastecimiento, Instituto Mexicano del Seguro \\ Social, Hospital General Regional No. 1, Cuernavaca, \\ Morelos, México
}




\section{Introduction}

Although there has been a national cervical cancer screening program in Mexico since 1974 [1], and despite technological and scientific advances, this disease is the second leading cause of death due to cancer for Mexican women [2]. A recent study that evaluated the effect of the national cervical cancer screening program in Mexico reports that there has been a modest but significant decrease in mortality due to this cancer [3]. Although one of the main determinants of this decrease is an increase in early detection through the Pap smear, the authors report that the persistent low rates of high-grade cervical lesions detected are due to the poor quality that exists in the Pap smear collection process and especially in cytologic diagnosis. One of the recommendations of this study is to integrate diverse screening strategies, such as combining the Pap smear with human papillomavirus (HPV) testing to the cervical cancer screening program of Mexico[3].

The official recognition of HPV infection as a necessary cause of cervical cancer [4] has generated an interest in the use of HPV testing for screening and prevention efforts [5]. In order to evaluate the potential role of HPV testing in cervical cancer screening, it is important to consider the benefits and costs associated with this alternative technology and compare them to the benefits and costs associated with Papanicolau (Pap) cytology. The Pap test is currently the main cervical cancer-screening tool used around the world, and in some countries, it has significantly reduced the disease burden from cervical cancer [6, 7]. Research efforts have documented that a well-organized cervical cancer screening program can potentially reduce cervical cancer by $60-90 \%$ in the 3 years after screening $[8,9]$. However, studies have also shown that there are multiple factors that contribute to the ineffectiveness of many cervical cancer screening programs, including the high false negative rates of the Pap test, which may result in a misdiagnosis or delayed diagnosis. Other factors include poor quality of care, lack of access to screening and medical services, and poor follow-up for women with abnormal results $[10,11]$. Several studies have reported a Pap test sensitivity that ranges from $40-80 \%$ for high-grade cervical intraepithelial neoplasia (CIN) 2/3 [12-14]. The low sensitivity of the Pap results in a reported false negative rate of 25 to $50 \%$ [15]. The less-than-optimal performance of the conventional Pap test has helped generate the development of alternative screening technologies such as liquid-based cytology, the automated re-screening of smears, HPV testing, and visual inspection.

Two relatively recent meta-analyses, which report the findings of several published studies, indicate that HPV DNA testing has a greater sensitivity than the Pap test, for detecting high-grade CIN [16, 17]. These meta-analyses both indicate that primary screening with the Hybrid Capture 2 (HC2) HPV DNA test detects approximately $20 \%$ more high-grade CIN or cancer compared to cytology at the atypical squamous cells of undetermined significance (ASCUS) cut-off, but is less specific [16, 17]. Arbyn et al. conclude that by combining HPV and cytology screening, $4 \%$ more CIN-3 lesions can be identified, although this comes at the expense of a $7 \%$ loss in specificity, in comparison with only screening for HPV [17]. In the United States, the use of combined cytology and HPV primary screening has been approved for women older than 30 years [18]. However, in most countries, cytology-based screening still remains the standard screening method.

Numerous studies have examined the cost-effectiveness of cervical cancer screening with HPV DNA testing as compared to Pap. A study by Goldhaber-Fiebert et al. used an empirical model of the natural history of cervical cancer to assess the quality-adjusted life years (QALYs), lifetime costs, and incremental cost-effectiveness ratios of HPV DNA testing compared to cytology screening with the Pap test. The authors conclude that age-based screening with HPV DNA testing as a triage test for equivocal results in younger women, and as a primary screening test in older women, is expected to be more cost-effective than current screening practices in the United States [19]. Another study by Kim et al. assessed the cost-effectiveness of incorporating HPV DNA testing into existing cervical cancer screening programs in the United Kingdom, The Netherlands, France, and Italy. They found that HPV DNA testing strategies were more effective than each country's existing screening policy and concluded that HPV DNA testing has the potential to improve health benefits at a reasonable cost compared with current screening policies in these European countries [20].

Several recent studies recommend that based on the strong evidence concerning cervical cancer prevention technologies, including the expected impact of vaccination on the performance of cytology, a reformulation of cervical cancer screening policies should be based on HPV testing using validated methods followed by cytologic triage [21-23]. These studies provide important information about the cost-effectiveness of HPV testing for cervical cancer screening. However, the results of most of these studies are based on cost and effectiveness parameters that were estimated using previously published data from many different sources and are not necessarily specific to Mexico.

We conducted an economic evaluation of HPV testing that is based on the actual cost and effectiveness data obtained from the cervical cancer screening program at the Mexican Institute of Social Security (IMSS) in Morelos, Mexico. IMSS is one of the key institutions in the Mexican health system, which provides health care services to 
approximately $43 \%$ of the population [24]. The coverage of the IMSS cervical cancer screening program is estimated to be $50 \%$. The purpose of this cost-effectiveness analysis (CEA) is to determine the incremental costs and effects of using HPV testing as a screening technique for the detection of cervical cancer, in Mexico. We hope that the results of this study will provide useful evidence to policy-makers who will decide whether to incorporate the use of HPV testing as part of the IMSS cervical cancer screening program.

\section{Materials and methods}

\section{Study design and population}

This CEA used data obtained from the initial enrollment phase of the Morelos HPV Study. The specifics regarding the study design, methodology and baseline characteristics of participants have been detailed elsewhere [25], and the ethical committees of all participating institutions approved the study protocol and consent forms for this study. The Morelos HPV Study was conducted to examine the potential use of HPV testing for cervical cancer screening in Mexico. The costs and health outcomes of the following interventions were evaluated and compared: (1) not conducting cervical cancer screening, (2) using only the Pap test, (3) using only self-HPV testing, (4) using only clinician-HPV testing, and (5) using the clinician-HPV test in conjunction with the Pap test. These five different strategies were evaluated in the context of screening for two different age groups, women aged 20-80 and 30-80. For this analysis, the costs associated with using a clinic-based self-HPV test, the clinician-HPV test, and the Pap test were identified and quantified. All costs are presented in 2008 US dollars. The health outcome is the number of histologically confirmed cases of CIN $2 / 3$ or cervical cancer detected.

This CEA was performed from the perspective of the health sector. The time horizon for this CEA is 1 year, during which all the screening and follow-up activities occur at the IMSS medical facilities. The target population for this CEA is female IMSS clients, between the ages of 20-80, in the state of Morelos. This CEA was designed to capture the most significant effects that the different cervical cancer screening interventions would have on the target population.

Identification and calculation of costs

Costs were estimated using micro-costing techniques, which consist of measuring and appraising every resource required to produce a service or final good [26]. The IMSS direct medical costs associated with both types of HPV testing and Pap testing were determined individually for each screening method $[27,28]$. The IMSS direct medical costs for the Pap, self-, and clinician-HPV tests were calculated taking into account: (1) screening costs, including the cost of sample collection, reagents and laboratory staff; (2) costs of follow-up care for all positive results such as colposcopy costs, which include the cost of performing a colposcopy exam and taking a biopsy if necessary, the laboratory costs of determining a biopsy-confirmed diagnosis, and in the case of true positives, the cost to treat a case of CIN 2/3 or cervical cancer; and (3) costs of false negatives.

Each of these costs includes the product of price times the quantity of material and human resources that were used to complete each process. A time and motion (TAM) study was carried out at IMSS and at the National Institute of Public Health of Mexico (INSP) to identify the time, quantity, labor, and equipment costs associated with each of these processes. A list of all the personnel involved in collecting Pap specimens was obtained as part of the TAM study that was conducted. These workers were observed to determine their job responsibilities and productivity. The direct medical costs were determined by multiplying the price (or unit cost) by the quantity used; the price and quantity used for each process were also reported separately. A discount rate of $3 \%$ (over the useful life of the equipment) was used to calculate the equivalent annual cost of equipment expenditures.

Staff costs were calculated by multiplying the amount of time spent on each task by each worker, by the hourly rate that each employee is paid to perform the task. The rates of pay were obtained from the Morelos IMSS personnel office and the INSP personnel office. Supply costs were determined by multiplying the units or amounts of goods consumed, by the price that was paid to purchase the good. These prices were obtained from the IMSS purchasing catalog, the INSP HPV lab purchasing orders, and market prices. Overhead and capital costs [29] were obtained from the IMSS Office of Construction, Conservation, and Equipment, from the Morelos IMSS administrative offices, and from the INSP administrative offices. A discount rate of $3 \%$ over 50 years was used to annuitize capital expenditures.

Future follow-up costs and benefits were assumed to occur in the same year as screening and did not need to be discounted. A sensitivity analysis was performed using the lower and upper bounds of the costs and outcomes. The reference case costs and unconditional probabilities were assigned minimums and maximums based on the observed $95 \%$ confidence intervals (CIs) or a range of $\pm 25 \%$ (Table 1). 
Table 1 Parameters values of the model
HVP: human papillomavirus; CIN: cervical intraepithelial neoplasia

a Sensitivity and specificity estimates and $95 \%$ CIs from Salmeron (2002)

b Yvonne Flores, unpublished data

c Ruth Pérez, unpublished data

d Insinga [33]

\begin{tabular}{|c|c|c|c|}
\hline \multirow[t]{2}{*}{ Parameter } & \multirow[t]{2}{*}{ Base case Estimate } & \multicolumn{2}{|l|}{ Range } \\
\hline & & Min & Max \\
\hline \multicolumn{4}{|l|}{ Test performance (Sensitivity) ${ }^{\mathrm{a}}$} \\
\hline \multicolumn{4}{|l|}{ Women $20-80$} \\
\hline Cervical cytology (Pap test) & 59.4 & 49.2 & 68.9 \\
\hline Self-HPV test & 71.3 & 61.3 & 79.6 \\
\hline Clinician HPV test & 93.1 & 85.8 & 96.9 \\
\hline Clinician HPV test + Pap test & 98.0 & 92.3 & 99.7 \\
\hline \multicolumn{4}{|l|}{ Women $30-80$} \\
\hline Cervical cytology (Pap test) & 62.9 & 52.0 & 72.7 \\
\hline Self-HPV test & 68.5 & 57.7 & 77.8 \\
\hline Clinician HPV test & 92.1 & 83.9 & 96.5 \\
\hline Clinician HPV test + Pap test & 97.8 & 91.4 & 99.6 \\
\hline \multicolumn{4}{|l|}{ Test performance (Specificity) ${ }^{\mathrm{a}}$} \\
\hline \multicolumn{4}{|l|}{ Women $20-80$} \\
\hline Cervical cytology (Pap test) & 98.3 & 98.0 & 98.6 \\
\hline Self-HPV test & 89.2 & 88.5 & 89.9 \\
\hline Clinician HPV test & 91.8 & 91.2 & 92.4 \\
\hline Clinician HPV test + Pap test & 91.1 & 90.5 & 91.8 \\
\hline \multicolumn{4}{|l|}{ Women $30-80$} \\
\hline Cervical cytology (Pap test) & 98.2 & 97.8 & 98.5 \\
\hline Self-HPV test & 89.6 & 88.8 & 90.3 \\
\hline Clinician HPV test & 92.2 & 91.5 & 92.9 \\
\hline Clinician HPV test + Pap test & 91.4 & 90.7 & 92.1 \\
\hline \multicolumn{4}{|l|}{ Screening and treatment costs (in 2008 USD) } \\
\hline Self-HPV testing cost results & 14.15 & 10.61 & $17.69^{\mathrm{b}}$ \\
\hline Clinician-HPV testing cost results & 20.06 & 15.05 & $25.08^{\mathrm{b}}$ \\
\hline Clinician-HPV testing + Pap testing cost results & 26.18 & 19.64 & $32.73^{\mathrm{b}}$ \\
\hline Pap testing cost results & 13.20 & 9.90 & $16.50^{\mathrm{c}}$ \\
\hline Total cost colposcopy without a biopsy & 37.41 & 28.06 & $46.76^{\mathrm{c}}$ \\
\hline Total cost colposcopy with a biopsy & 64.86 & 48.65 & $81.08^{\mathrm{c}}$ \\
\hline Total cost pathology & 24.69 & 18.52 & $30.86^{\mathrm{c}}$ \\
\hline Average cost CIN $2 / 3$ treatment & 1,610 & 1,207 & $2,012^{\mathrm{d}}$ \\
\hline Average cost cervical cancer treatment & 8,421 & 7,806 & $8,637^{\mathrm{d}}$ \\
\hline Prevalence CIN 2/3/cervical cancer & 0.013 & 0.0098 & $0.0163^{\circ}$ \\
\hline
\end{tabular}

Identification and calculation of health outcomes

This CEA is based on the baseline screening results of the Morelos HPV Study [30]. The number of CIN 2/3 and cervical cancer cases that were detected using each screening strategy was used as the measure of effectiveness for this CEA. All cases were identified using histological results as the gold standard. This measure of effectiveness was chosen because it represents one of the main objectives of the IMSS screening program, which is to detect as many cases as possible, as early as possible, in order to avoid progression of disease and death. Although CIN 2/3 is not as serious as cervical cancer, most CIN $2 / 3$ cases are at greater risk of progressing to cancer if they are undetected
[31], which is why we evaluated both outcomes together. The sensitivity and specificity results from the Morelos HPV Study [30] that were used for this study (Table 1) are comparable to the findings of two recent meta-analyses that examined the diagnostic accuracy of HPV and Pap testing for primary cervical cancer screening [16, 17].

\section{Cost-effectiveness evaluation}

A decision tree model was used to estimate the costeffectiveness of the various screening strategies (Fig. 1). Decision tree models are used to represent the sequence of chance events and decisions that occur during a specific period of time. The probabilities assigned to each chance 
Fig. 1 Screening strategy decision tree

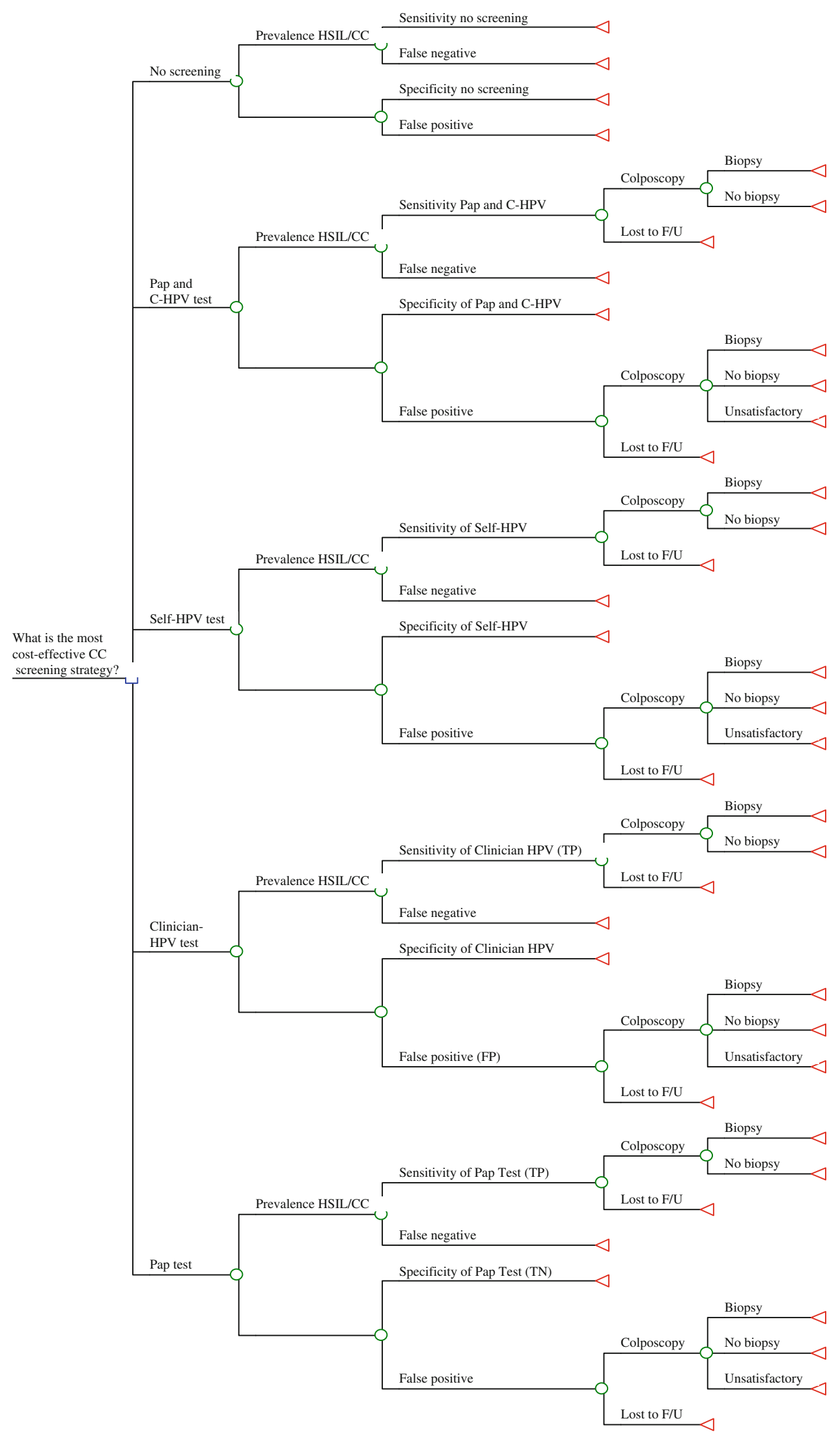


occurrence are often estimated using data from clinical studies [32]. Each branch of the decision tree represents one of the possible sequences of chance and decision events that could occur, which is in turn associated with a specific consequence that is valued based on its desirability. For this study, five cervical cancer screening strategies (decision tree branches) were evaluated by calculating their incremental cost-effectiveness ratios (ICERs) [32].

Although the specific probability of disease was the same for all five screening strategies; each strategy was assigned a specific sensitivity and specificity. Each individual or combined screening strategy also was assigned a series of costs that are associated with the specific number of CIN 2/3 and CC cases that were detected. The costs associated with each end point were assigned various codes (e.g. the cost of both a Pap test and HPV test, the cost of a colposcopy, the cost of a colposcopy with a biopsy, etc.), and the probabilities of each outcome (CIN 2/3 and CC detected vs. no CIN $2 / 3$ or CC detected) were also coded. The specific probabilities associated with each event were determined from the baseline results obtained from the Morelos HPV Study.

Our model assumes non-informative censoring of women who were lost to follow-up, i.e. that attrition was random with respect to health outcomes and costs. We estimated the average cost to treat a case of CIN 2/3 at IMSS in Morelos to be $\$ 1,610$ dollars (with a range of $\$ 1,207$ $\$ 2,012$ U.S.D.), and the estimated average cost to treat a case of cervical cancer to be $\$ 8,421$ dollars (with a range of $\$ 7,806-\$ 8,637$ U.S.D.), these treatment costs were obtained from previously published estimates in Mexico [33]. The size of the hypothetical cohort was set at 10,000 women aged 20-80, with 6,680 women in the hypothetical cohort aged 30-80. These 6,680 women represent the proportion of women from the 10,000 women cohort who would be between the ages of $30-80$ and 3,320 between 20 and 29 years of age. These numbers were estimated using the national population totals from the Mexican 2000 Census.

The cost-effectiveness ratio (CER) of the different screening strategies were plotted to determine which strategies were dominated (not cost-effective as compared to other more cost-effective options). The incremental costeffectiveness ratios (ICERs) of the various screening strategy options were compared to determine the most costeffective, undominated screening options. The ICER, for comparing alternatives to each other, is the difference in their cost divided by the difference in their effectiveness, or $\Delta$ Cost/ $\Delta$ Effectiveness.

Although it was hypothesized that the Pap test on its own would be dominated by the other screening strategies, it was important to compare each of the screening alternatives to the existing technology that is used to detect cervical cancer and will continue to be used at IMSS, as well as to the option of a no screening strategy. The costeffectiveness analysis was performed using Microsoft Excel (Microsoft Windows XP) and @Risk 5.0 (Palisade corporation 2009). All costs are reported in 2008 U.S.D.

A sensitivity analysis was performed to investigate how the predicted cost per case prevented would change when modifying the parameters. The following variables were considered for the sensitivity analysis: sensitivity of the screening tests, cost of screening tests, and treatment costs. The results of a recently published paper that reports the sensitivity and specificity of the Pap and HPV tests in a sample of 50,000 women who use IMSS services in Mexico were used to calibrate the model [34].

\section{Results}

Direct medical costs

Our results indicate that the total cost of the self-HPV test is $\$ 14.15$ U.S.D.; the total cost of the clinician-HPV test is \$20.06 U.S.D.; the total cost of performing both a clinician-HPV test and a Pap is $\$ 26.18$ U.S.D.; and the total cost of a Pap test is $\$ 13.20$ U.S.D. The total cost to perform a colposcopy exam without taking a biopsy specimen is \$37.41 U.S.D.; the total cost to perform a colposcopy exam that includes a biopsy specimen is $\$ 64.86$ U.S.D.; and the total cost to evaluate the biopsy and make a histological diagnosis is $\$ 24.69$ U.S.D.

\section{Identification of health outcomes}

The results of the Morelos HPV Study indicate that when women aged 20 to 80 years are screened to detect CIN 2/3 and cervical cancer, the sensitivity of the Pap test is 59.4 (95\% CI 49.2-68.9) and its specificity is 98.3 (95\% CI 98.0-98.6) [30]. The sensitivity of the self-HPV test is 71.3 (95\% CI 61.3-79.6) and its specificity is 89.2 (95\% CI 88.5-89.9), and the sensitivity of the clinician-HPV test is 93.1 (95\% CI 85.8-96.9) and its specificity is 91.8 (95\% CI 91.2-92.4). When used to screen women between the ages of 20-80, the sensitivity of the Pap and clinician-HPV test combination is 98.0 (95\% CI 92.3-99.7) and its specificity is 91.1 (95\% CI 90.5-91.8) [30].

The total program costs associated with each of the screening strategies was determined based on the cost of the true-positive, false-positive, true-negative, and falsenegative cases that were identified. Table 2 shows a breakdown of the costs associated with each screening strategy based on diagnostic performance when used to screen women between the ages of $20-80$ and women aged 30-80. Although the cost to perform a Pap test at IMSS is $\$ 13.20$ U.S.D., the average cost to screen one woman aged 
Table 2 Total cost of screening women aged $20-80$ and 30-80 for each strategy

\begin{tabular}{|c|c|c|c|c|c|}
\hline & No Screening & Pap & Self-HPV & C-HPV & Pap and C-HPV \\
\hline \multicolumn{6}{|c|}{ Women $20-80(n=10,000)$} \\
\hline True positives & 0 & 78 & 93 & 122 & 128 \\
\hline True negatives & 0 & 9,701 & 8,803 & 9,060 & 8,991 \\
\hline False positives & 0 & 168 & 1,066 & 809 & 878 \\
\hline False negatives & 131 & 53 & 38 & 9 & 3 \\
\hline Cost of screening test & $\$ 0.00$ & $\$ 13.20$ & $\$ 14.15$ & $\$ 20.06$ & $\$ 26.18$ \\
\hline Cost of true positives & $\$ 0.00$ & $\$ 133,594.50$ & $\$ 159,374.10$ & $\$ 209,792.42$ & $\$ 220,893.44$ \\
\hline Cost of true negatives & $\$ 0.00$ & $\$ 128,053.20$ & $\$ 124,562.45$ & $\$ 181,743.60$ & $\$ 235,384.38$ \\
\hline Cost of false positives & $\$ 0.00$ & $\$ 13,206.30$ & $\$ 67,188.02$ & $\$ 57,074.83$ & $\$ 67,587.82$ \\
\hline Cost of false negatives & $\$ 1,103,151.00$ & $\$ 447,012.60$ & $\$ 320,535.70$ & $\$ 75,969.54$ & $\$ 25,341.54$ \\
\hline Total program cost & $\$ 1,103,151.00$ & $\$ 721,866.60$ & $\$ 671,660.27$ & $\$ 524,580.39$ & $\$ 549,207.18$ \\
\hline Total cost per woman & $\$ 110.32$ & $\$ 72.19$ & $\$ 67.17$ & $\$ 52.46$ & $\$ 54.92$ \\
\hline \multicolumn{6}{|l|}{ Women $30-80(n=6,680)$} \\
\hline True positives & 0 & 82 & 90 & 121 & 128 \\
\hline True negatives & 0 & 6,431 & 5,868 & 6,038 & 5,986 \\
\hline False positives & 0 & 118 & 681 & 511 & 563 \\
\hline False negatives & 131 & 49 & 41 & 10 & 3 \\
\hline Cost of screening test & $\$ 0.00$ & $\$ 13.20$ & $\$ 14.15$ & $\$ 20.06$ & $\$ 26.18$ \\
\hline Cost of true positives & $\$ 0.00$ & $\$ 140,445.50$ & $\$ 154,233.00$ & $\$ 208,072.81$ & $\$ 220,893.44$ \\
\hline Cost of true negatives & $\$ 0.00$ & $\$ 84,889.20$ & $\$ 83,032.20$ & $\$ 121,122.28$ & $\$ 156,713.48$ \\
\hline Cost of false positives & $\$ 0.00$ & $\$ 9,164.91$ & $\$ 42,757.29$ & $\$ 36,074.75$ & $\$ 43,415.47$ \\
\hline Cost of false negatives & $\$ 1,103,151.00$ & $\$ 413,275.80$ & $\$ 345,841.15$ & $\$ 84,410.60$ & $\$ 25,341.54$ \\
\hline Total program cost & $\$ 1,103,151.00$ & $\$ 647,775.41$ & $\$ 625,863.64$ & $\$ 449,680.44$ & $\$ 446,363.93$ \\
\hline Total cost per woman & $\$ 165.14$ & $\$ 96.97$ & $\$ 93.69$ & $\$ 67.32$ & $\$ 66.82$ \\
\hline
\end{tabular}

HPV: human papillomavirus, C-HPV: Clinician HPV test

Costs reported in 2008 US dollars

20-80 using the Pap test at IMSS is actually \$72.19 U.S.D. when one takes into account the cost of false negatives, false positives, true positives, and true negatives, in addition to the cost of the screening test. Likewise, while the cost of a self-HPV screening test is \$14.15 U.S.D., the average cost to screen one woman aged 20-80 using the self-HPV test is $\$ 67.17$. The cost of the clinician-HPV screening test is $\$ 20$ U.S.D., and the average cost to screen one woman aged 20-80 using the clinician-HPV test is estimated at \$52.46. The Pap and clinician-HPV screening test combination is $\$ 26.18$ U.S.D., while the average cost to screen one woman aged 20-80 using the Pap and clinician-HPV test combination is $\$ 54.92$ (Table 2).

\section{Reference case cost-effectiveness analysis}

Five different cervical cancer screening strategies were compared to determine the most cost-effective option(s) in two age groups of women (20-80 and 30-80). Table 3 presents the incremental cost-effectiveness results of ten different cervical cancer screening interventions from the perspective of IMSS. The following screening strategies were found to be viable: (1) Pap and clinician-HPV testing of women aged 30-80, (2) Clinician-HPV testing for women 30-80, and (3) Pap and clinician-HPV testing of women aged 20-80. The three dominated strategies in both age groups were self-administered HPV testing, Pap testing alone, and no screening. Figure 2 provides a graphical representation of the incremental cost-effectiveness of these screening strategies.

Additionally, when the model was calibrated by using a Pap test sensitivity of $40 \%$, as recently reported by Lazcano et al. [34], we found that the cost-effectiveness ratio increased from a base case result of $\$ 9,352$ to $\$ 17,060$ USD for women $20-80$, and from $\$ 8,416$ to $\$ 16,159$ USD for women 30-80 (Data not shown).

Sensitivity analysis

Table 4 presents the results of the one-way sensitivity analysis that was performed. Of the parameters that were explored, the sensitivity of the screening tests had the greatest effect on the cost-effectiveness results. The costeffectiveness ratios varied by as much as 38 and $37 \%$, respectively, when a low sensitivity was used for both the 
Table 3 Incremental cost-effectiveness of ten cervical cancer screening strategies

\begin{tabular}{|c|c|c|c|c|c|c|c|}
\hline Screening strategy & $\begin{array}{l}\text { (A) Program } \\
\text { costs }\end{array}$ & $\begin{array}{l}\text { (B) Cost of } \\
\text { missed CC cases }\end{array}$ & $\begin{array}{l}\text { (C) Total } \\
\text { cost }\end{array}$ & $\begin{array}{l}\text { (D) } \\
\text { Incremental } \\
\text { cost }\end{array}$ & $\begin{array}{l}\text { (E) Total } \\
\text { cases } \\
\text { detected }\end{array}$ & $\begin{array}{l}\text { (F) } \\
\text { Incremental } \\
\text { cases detected }\end{array}$ & $\begin{array}{l}\text { (G) Incremental } \\
\text { Cost/ } \\
\text { Effectivenes } \\
\text { Ratio (ICER) }\end{array}$ \\
\hline $\begin{array}{l}\text { Pap and Clinician-HPV test } \\
(30-80 \mathrm{y})\end{array}$ & $\$ 421,022$ & $\$ 25,342$ & $\$ 446,364$ & - & 128 & - & \\
\hline Clinician-HPV test (30-80 y) & $\$ 365,270$ & $\$ 84,411$ & $\$ 449,681$ & $\$ 3,317$ & 121 & - & Dominated $^{\mathrm{a}}$ \\
\hline Clinician-HPV test $(20-80 \mathrm{y})$ & $\$ 448,611$ & $\$ 75,970$ & $\$ 524,581$ & $\$ 78,217$ & 122 & - & Dominated $^{\mathrm{a}}$ \\
\hline $\begin{array}{l}\text { Pap and clinician-HPV test } \\
(20-80 \text { y) }\end{array}$ & $\$ 523,865$ & $\$ 25,342$ & $\$ 549,207$ & $\$ 102,843$ & 128 & - & Dominated $^{\mathrm{a}}$ \\
\hline Self-HPV test $(30-80$ y) & $\$ 280,023$ & $\$ 345,841$ & $\$ 625,864$ & $\$ 179,500$ & 90 & - & Dominated $^{\mathrm{a}}$ \\
\hline Pap test $(30-80 \mathrm{y})$ & $\$ 234,499$ & $\$ 413,276$ & $\$ 647,775$ & $\$ 201,411$ & 82 & - & Dominated $^{\mathrm{a}}$ \\
\hline Self-HPV test $(20-80 \mathrm{y})$ & $\$ 351,125$ & $\$ 320,536$ & $\$ 671,661$ & $\$ 225,297$ & 93 & - & Dominated $^{\mathrm{a}}$ \\
\hline Pap test $(20-80 \mathrm{y})$ & $\$ 274,854$ & $\$ 447,013$ & $\$ 721,867$ & $\$ 275,503$ & 78 & - & Dominated $^{\mathrm{a}}$ \\
\hline No screening (20-80 y) & $\$ 0$ & $\$ 1,103,151$ & $\$ 1,103,151$ & $\$ 656,787$ & 0 & - & Dominated $^{\mathrm{a}}$ \\
\hline No screening (30-80 y) & $\$ 0$ & $\$ 1,103,151$ & $\$ 1,103,151$ & $\$ 653,470$ & 0 & - & Dominated $^{\mathrm{a}}$ \\
\hline
\end{tabular}

Assessed for base-case: prevalence of CIN 2/3 and cervical cancer (CC) was 1.3\%. All costs are in 2008 US dollars

(A) Program costs include fixed and variable costs associated with the cost of baseline screening test and follow-up confirmatory tests such as colposcopy and histology

(B) The estimated cost of subsequent treatment for an undetected case of CC is $\$ 8,421$ US dollars; the cost of lost CC cases $=$ Number of undetected $\mathrm{CC}$ cases $(131-(\mathrm{D})) \times \$ 8,421$

(C) Total program costs $=$ Program costs (A) + Cost of missed CC cases (false negatives) (B). (See Table 1)

(D) The incremental cost is the difference in cost between each strategy and the next best undominated strategy

(E) Number of CIN 2/3 and CC cases detected by the specified screening strategy

(F) The difference in the number of cases detected by each of the three undominated screening strategies

(G) Incremental cost/effectiveness ratio = Incremental cost/incremental CIN 2/3 and CC cases detected

a A dominated strategy costs more and is less effective than the undominated strategies

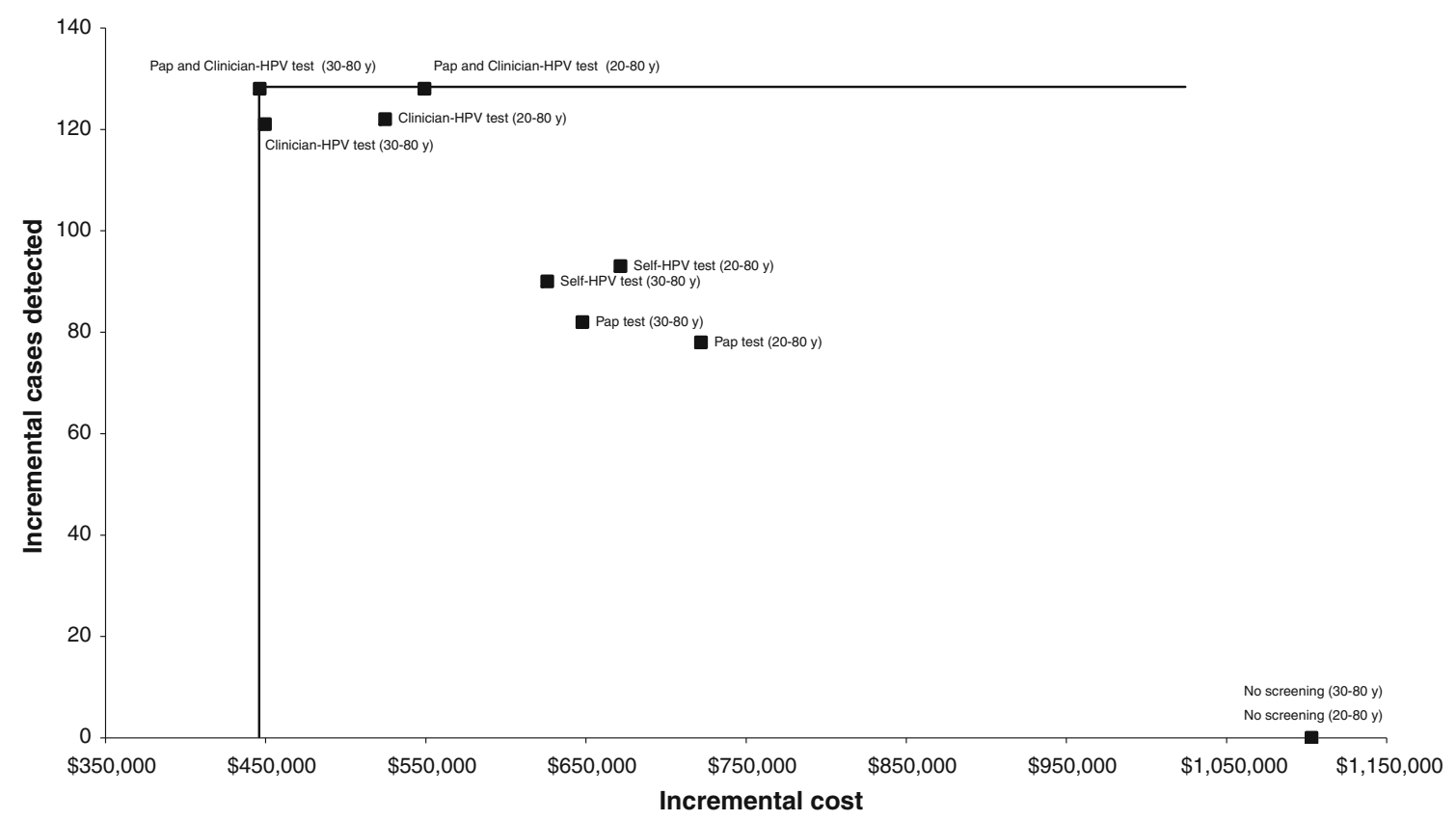

Fig. 2 Cost-effectiveness of 10 cervical cancer screening strategies*

* Note: The points along the lines represent non-dominated strategies that are cost-effective. The points below the lines represent dominated strategies that are not cost-effective 
Table 4 One-way sensitivity analysis results

\begin{tabular}{|c|c|c|c|c|c|c|c|}
\hline \multirow[t]{2}{*}{ Test } & \multicolumn{3}{|c|}{ Varying sensitivity of tests } & \multicolumn{2}{|c|}{ Varying costs of tests } & \multicolumn{2}{|c|}{$\begin{array}{l}\text { Varying costs of treatment } \\
\text { (CIN2/3 and CC) }\end{array}$} \\
\hline & Base case & Low estimate & High estimate & Low estimate & High estimate & Low estimate & High estimate \\
\hline \multirow[t]{2}{*}{ Pap 20-80 } & 9,277 & 12,613 & 7,085 & 8,827 & 9,775 & 8,470 & 9,843 \\
\hline & & $+36 \%$ & $-24 \%$ & $-5 \%$ & $+5 \%$ & $-9 \%$ & $+6 \%$ \\
\hline \multirow[t]{2}{*}{ Pap 30-80 } & 7,861 & 10,879 & 5,868 & 7,516 & 8,142 & 7,063 & 8,358 \\
\hline & & $+38 \%$ & $-25 \%$ & $-4 \%$ & $+4 \%$ & $-10 \%$ & $+6 \%$ \\
\hline \multirow[t]{2}{*}{ Self-HPV 20-80 } & 7,191 & 9,427 & 5,714 & 6,621 & 7,703 & 6,511 & 7,651 \\
\hline & & $+31 \%$ & $-21 \%$ & $-8 \%$ & $+7 \%$ & $-9 \%$ & $+6 \%$ \\
\hline \multirow[t]{2}{*}{ Self-HPV 30-80 } & 6,975 & 9,562 & 5,355 & 6,616 & 7,373 & 6,309 & 7,496 \\
\hline & & $+37 \%$ & $-23 \%$ & $-5 \%$ & $+6 \%$ & $-10 \%$ & $+7 \%$ \\
\hline \multirow[t]{2}{*}{ Clin-HPV 20-80 } & 4,301 & 5,241 & 3,871 & 3,786 & 4,821 & 3,855 & 4,721 \\
\hline & & $+22 \%$ & $-10 \%$ & $-12 \%$ & $+12 \%$ & $-10 \%$ & $+10 \%$ \\
\hline \multirow[t]{2}{*}{ Clin-HPV 30-80 } & 3,727 & 4,770 & 3,269 & 3,393 & 4,100 & 3,291 & 4,167 \\
\hline & & $+28 \%$ & $-12 \%$ & $-9 \%$ & $+10 \%$ & $-12 \%$ & $+12 \%$ \\
\hline \multirow[t]{2}{*}{ Pap \& Clin-HPV 20-80 } & 4,278 & 4,938 & 4,071 & 3,640 & 4,878 & 3,843 & 4,278 \\
\hline & & $+15 \%$ & $-5 \%$ & $-15 \%$ & $+14 \%$ & $-10 \%$ & $+9 \%$ \\
\hline \multirow[t]{2}{*}{ Pap \& Clin-HPV 30-80 } & 3,484 & 4,192 & 3,293 & 3,059 & 3,898 & 3,061 & 3,885 \\
\hline & & $+20 \%$ & $-5 \%$ & $-12 \%$ & $+12 \%$ & $-12 \%$ & $+12 \%$ \\
\hline
\end{tabular}

Cost-effectiveness ratios (cost per case prevented of CIN2/3 or cancer)

In US dollars of 2008 year. (Base case scenario is the total costs divided by cases detected)

Pap and self-HPV tests. Varying the cost of the screening test had a greater effect on the cost-effectiveness ratios of the clinician-HPV test and the Pap and clinician-HPV test combination. Varying the costs of treatment also had a slightly greater effect on the cost-effectiveness ratios of the clinician-HPV test and the Pap and clinician-HPV test combination.

\section{Discussion}

The results of this CEA indicate that screening women between the ages of 30-80 for cervical cancer using clinical-HPV testing or the combination of clinical-HPV testing and the Pap is always more cost-effective than using the Pap test alone. HPV testing for women aged 30-80 was found to be more cost-effective than screening women between the ages of 20-80. The total cost to perform a clinician-HPV test (\$20 U.S.D.) and the clinician-HPV and Pap test combination (\$26.18 U.S.D.) are higher than the cost of the self-HPV test (\$14.15 U.S.D.) and the Pap test (\$13.20 U.S.D.). But when one reckons the cost of false negatives, false positives, true positives, and true negatives, in addition to the cost of the screening test, the total costs associated with the self-administered HPV test and the Pap test exceed those of tests with fewer false negatives. When one considers the costs of missed cases, the clinician-HPV test emerges as the least expensive option (\$52.46 U.S.D. per case detected), because it is able to detect $93 \%$ of all cervical cancer cases. The use of the Pap and clinicianHPV test combination is the next least expensive screening option (\$54.92 U.S.D. per case detected) with the ability to identify $98 \%$ of cervical cancer cases, which represents 64\% more cases than the Pap test on its own.

There are certain factors that should be considered when deciding which HPV screening strategy is the most appropriate, based on the results of this CEA. If an organization such as IMSS is already spending more money on Pap testing than it would using HPV testing, it might be better to implement a more cost-effective cervical cancer screening strategy such as clinician-HPV testing. Our results indicate that clinician-HPV testing is significantly more effective at detecting CIN 2/3 and cervical cancer cases and is less expensive than the Pap test, when one considers the average costs incurred by the tests. The Pap and clinician-HPV test combination could also be taken into account, since it is only slightly more expensive than clinician-HPV testing, and is able to detect a greater number of CIN 2/3 and cervical cancer cases than either the Pap or clinician-HPV test on its own.

Deciding which HPV testing strategy is the most appropriate depends not only on the cost and effectiveness of each option, but on the specific needs and circumstances of the organizations or communities that will be affected by the implementation of HPV testing. In developing countries that have little or no cervical cancer screening infrastructure, the 
self-HPV testing strategy may be more appropriate [35, 36]. Self-HPV testing can be performed in a non-clinical setting, without the participation of medical personnel. Women can collect their own vaginal specimens basically anywhere, including in the comfort of their own homes, using an easy to use self-HPV test collection kit. The laboratory facilities required to perform the HPV testing are inexpensive, simple to mount, take up little space, and can be staffed by personnel that can be trained in just a few weeks [37]. Since HPV testing procedures are semi-automated, there is a lower probability of human error than with Pap testing.

However, the use of self-HPV testing may not be an appropriate option for countries such as Mexico that have a well-established, though not necessarily effective, national cervical cancer screening program. Implementing a completely different screening program that disregards the existing cervical cancer screening resources and infrastructure might not be an effective or feasible alternative. A more appropriate course of action would be to incorporate a screening strategy that makes use of the existing clinical resources and infrastructure to improve the quality and effectiveness of the cervical cancer screening program. Implementing the use of the clinician-HPV test, or the Pap and clinician-HPV test combination, would greatly improve the case detection capabilities of the IMSS cervical cancer screening program in Mexico, at little or no additional cost. However, even in Mexico, self-HPV testing could be considered the more appropriate and acceptable cervical cancer screening option for women who have a difficult time getting to and from a clinic setting, or who refuse to undergo a pelvic exam [38].

A recent study by Goldie et al. used empirically calibrated models to assess the cost-effectiveness of HPV vaccination for 33 countries in Latin America and the Caribbean, including Mexico [39]. Although this study focused on the use of HPV vaccination to prevent cervical cancer, the authors also assessed screening with cytology 3 times per lifetime at $70 \%$ coverage, HPV vaccination, and HPV vaccination plus screening with HPV DNA testing 3 times per lifetime at $70 \%$ coverage, and concluded that HPV DNA testing was the most effective and cost-effective of the screening strategies [39]. Another study investigated the cost-effectiveness of different cervical cancer prevention strategies in Mexico [40]. The results of this study, which uses data obtained from the Ministry of Health $(\mathrm{MoH})$ of Mexico, also indicate that the combined use of the Pap and HPV test is a cost-effective screening option [40].

One of the strengths of this CEA is that it uses the results of a population-based screening program that was specifically designed to evaluate the use of HPV testing to detect cervical cancer. This is the first CEA that compares the use of HPV testing to the Pap test in Mexico, using program costs and effectiveness parameters that were obtained from the IMSS cervical cancer screening program. The goal of this CEA is inform decision makers at IMSS about the potential benefits of incorporating the HPV test as part of the national cervical cancer screening program.

A limitation of this study is the assumption that the cost of a missed case of cervical cancer is $\$ 8,421$ U.S.D., and the cost to treat a case of CIN $2 / 3$ is $\$ 1,610$ U.S.D. These estimates are not based on direct measurements from the IMSS cervical cancer screening program in Morelos. Additional research should be conducted to determine the actual cost of a missed case of CIN 2/3 or cervical cancer at IMSS, because having more specific information would improve the CEA results. These CEA results are also limited in that they are cross-sectional. This analysis examines the cost-effectiveness of different cervical cancer options at one point in time. A CEA that evaluates the performance of HPV testing when compared to the Pap over the course of several years could provide additional data about the long-term cost-effectiveness of HPV testing in Mexico.

The results of this analysis suggest that the Pap test is not the most appropriate or cost-effective cervical cancer screening option for the IMSS cervical cancer screening program in Mexico. The findings of this CEA indicate that the Pap is less accurate and effective, in addition to being a more expensive screening option. The cost of the Pap test itself is not necessarily high, but the cost of the false negatives is significant. This CEA suggests that HPV testing could be a more cost-effective and appropriate cervical cancer screening alternative for a large, national health delivery organization such as IMSS. This finding is especially relevant now that the HPV vaccine is available in Mexico. The HPV vaccine is currently being offered to girls between the ages of 11 and 13 years at IMSS and the Secretaría de Salud (Mexican $\mathrm{MoH}$ ). The presence of an HPV vaccination program in Mexico is bound to change cervical cancer screening policies, with a move toward HPV screening in the near future. A cervical cancer screening program that includes HPV testing in the context of an HPV vaccination program is likely to be even more cost-effective and could also be used for the epidemiologic surveillance of the vaccine program.

Acknowledgments Financial support for this study was provided by the Instituto Mexicano del Seguro Social (IMSS), the Consejo Nacional para la Ciencia y Tecnología grant \# 26267 M, Insituto Nacional de Salud Pública, the National Institutes of Health grant \# U19 AI38533, and Digene Corporation.

Open Access This article is distributed under the terms of the Creative Commons Attribution Noncommercial License which permits any noncommercial use, distribution, and reproduction in any medium, provided the original author(s) and source are credited. 


\section{References}

1. Lazcano-Ponce EC, Moss S, Alonso R, Salmerón J, Hernández M (1999) Cervical cancer screening in developing countries: why is it ineffective? The case of Mexico. Arch Med Res 30(3):240-250

2. Palacio-Mejía LS, Lazcano-Ponce E, Allen-Leigh B, HernándezAvila M (2009) Regional differences in breast and cervical cancer mortality in Mexico between 1979-2006. Salud Pub Mex 51(2):S208-S219

3. Lazcano-Ponce E, Palacio-Mejia LS, Allen-Leigh B et al (2008) Decreasing cervical cancer mortality in Mexico: effect of Papanicolaou coverage, birthrate, and the importance of diagnostic validity of cytology. Cancer Epidemiol Biomarkers Prev 17:2808-2817

4. Walboomers JM, Jacobs MV, Manos MM et al (1999) Human papillomavirus is a necessary cause of invasive cancer worldwide. J Pathol 189:12-19

5. Lőrincz AT (2003) Screening for cervical cancer: new alternatives and research. Salud Pub Mex 45(3):S376-S387

6. Wang SS, Sherman ME, Hildesheim A, Lacey JV Jr, Devesa S (2004) Cervical adenocarcinoma and squamous cell carcinoma incidence trends among white women and black women in the United States for 1976-2000. Cancer 100(5):1035-1044

7. Almonte M, Murillo R, Sánchez GI, Jerónimo J, Salmerón J, Ferreccio C, Lazcano-Ponce E, Herrero R (2010) New paradigms and challenges in cervical cancer prevention and control in Latin America. Salud Pub Mex 52(6):544-559

8. IARC Working Group on the Evaluation of Cervical Cancer Screening Programmes (1986) Screening for squamous cervical cancer: duration of low risk after negative results of cervical cytology and its implication for screening policies. BMJ 293: 659-664

9. Sasieni P, Cuzick J, Farmery E (1995) Accelerated decline in cervical cancer mortality in England and Wales. Lancet 346(8989):1566-1567

10. Murillo R (2007) Cytology-based cervical cancer screening programmes in Latin America. HPV Today 12:6

11. Cuzick J, Meijer CJ, Walboomers JM (1998) Screening for cervical cancer. Lancet 351:1439-1440

12. Cuzick J, Sasieni P, Davies P, et al. (1999) A systematic review of the role of human papillomavirus testing within a cervical screening program. Health Technol Assess 3(14): i-iv, 1-196

13. Clavel C, Masure M, Bory JP et al (2001) Human papillomavirus testing in primary screening for the detection of high-grade cervical lesions: a study of 7932 women. Br J Cancer 84(12):1616-1623

14. Schiffman M, Herrero R, Hildesheim A et al (2000) HPV DNA testing in cervical cancer screening: Results from women in a high-risk province of Costa Rica. JAMA 283:87-93

15. Mandelblatt JS, Lawrence WF, Womack SM et al (2002) Benefits and costs of using HPV testing to screen for cervical cancer. JAMA 287(18):2372-2381

16. Koliopoulos G, Arbyn M, Martin-Hirsch P, Kyrgiou M, Prendiville W, Paraskevaidis E (2007) Diagnostic accuracy of human papillomavirus testing in primary cervical screening: a systematic review and meta-analysis of non-randomized studies. Gynecol Oncol 104(1):232-246

17. Arbyn M, Sasieni P, Meijer CJ, Clavel C, Koliopoulos G, Dillner J (2006) Chapter 9: clinical applications of HPV testing: a summary of meta-analyses. Vaccine 24(3): S3/78-89

18. Wright TC Jr, Schiffman M, Solomon D et al (2004) Interim guidance for the use of human papillomavirus DNA testing as an adjunct to cervical cytology for screening. Obstet Gynecol 103(2):304-309

19. Goldhaber-Fiebert JD, Stout NK, Salomon JA, Kuntz KM, Goldie SJ (2008) Cost-effectiveness of cervical cancer screening with human papillomavirus DNA testing and HPV-16, 18 vaccination. J Natl Cancer Inst 100(5):308-320
20. Kim JJ, Wright TC, Goldie SJ (2005) Cost-effectiveness of human papillomavirus DNA testing in the United Kingdom, The Netherlands, France, and Italy. J Natl Cancer Inst 97(12):888-895

21. Franco EL, Tsu V, Herrero R et al (2008) Integration of human papillomavirus vaccination and cervical cancer screening in Latin America and the Caribbean. Vaccine 26(11):L88-L95

22. Herrero R, Ferreccio C, Salmerón J et al (2008) New approaches to cervical cancer screening in Latin America and the Caribbean. Vaccine 26(11):L49-L58

23. Murillo R, Almonte M, Pereira A et al (2008) Cervical cancer screening programs in Latin America and the Caribbean. Vaccine 26(11):L37-L48

24. Instituto Mexicano del Seguro Social. Información estadística en Salud. Total nacional enero a octubre del 2009. En: http://www. imss.gob.mx/dpm/dis/Tabla.aspx?Srv=M00-1\&ID=SCES006_001_ 001\&OPC $=$ opc 03

25. Flores Y, Shah K, Lazcano E et al (2002) Design and methods of the evaluation of an HPV-based cervical cancer screening strategy in Mexico: the Morelos HPV study. Salud Pub Mex 44(4): 335-344

26. Drummond MF, Stoddart GL, Torrance GW, Stoddart GL, O'Brien BJ, O'Brien B (1997) Methods for the economic evaluation of health care programmes, 2nd edn. Oxford University Press, Oxford, pp 55-102

27. Drummond M F, Brandt A, Luce B, Rovira J (1993) Standardizing methodologies for economic evaluation in health care. In: Practice, problems, and potential. Int. J. Technol. Assess. Health Care Winter 9(1):26-36

28. Arredondo A, Damián T (1997) Costos económicos en la producción de los servicios de salud: del costo de los insumos al costo de manejo de caso. Salud Publica Mex 39:117-124

29. Tan S, Rutten F, Ineveld B, Redekop W (2009) Comparing methodologies for the cost estimation of hospital services. Eur $\mathrm{J}$ Health Econ 10:39-45

30. Salmerón J, Lazcano EC, Lőrincz AT et al (2003) Comparison of HPV-based assays with Papanicolaou smears for cervical cancer screening in Morelos State, Mexico. Cancer Causes Control 14:505-512

31. Schiffman M, Kjaer SK (2003) Chapter 2: natural history of anogenital human papillomavirus infection and neoplasia. J Natl Cancer Inst Monogr 31:14-19

32. Mandelblatt JS, Fryback DG, Weinstein MC, Russell LB, Gold MR, Hadorn DC (1996) Assessing the effectiveness of health interventions. In: Gold MR, Siegel JE, Russell LB, Weinstein MC (eds) Cost-effectiveness in health and medicine. Oxford University Press, New York, pp 135-175

33. Insinga RP, Dasbach EJ, Elbasha EH, Puig A, Reynales-Shigematsu LM (2007) Cost-effectiveness of quadrivalent human papillomavirus (HPV) vaccination in Mexico: a transmission dynamic model-based evaluation. Vaccine 26(1):128-139

34. Lazcano-Ponce E, Lörincz AT, Salmerón J, Fernández I, Cruz A, Hernández P, Mejia I, Hernández-Avila M (2010) A pilot study of HPV DNA and cytology testing in 50,159 women in the routine Mexican Social Security Program. Cancer Causes Control 21(10): 1693-700. Epub 2010 Jul 9

35. Barbee L, Kobetz E, Menard J et al (2010) Assessing the acceptability of self-sampling for HPV among Haitian immigrant women: CBPR in action. Cancer Causes Control 21(3):421-431

36. Serwadda D, Wawer M, Shah K et al (1999) Use of a hybrid capture assay of self-collected vaginal swabs in rural Uganda for detection of human papillomavirus. J Infect Dis 180:1316-1319

37. Qiao YL, Sellors JW, Eder PS et al (2008) A new HPV-DNA test for cervical-cancer screening in developing regions: a crosssectional study of clinical accuracy in rural China. Lancet Oncol 9(10):910-911 
38. Dzuba I, Yunes Díaz E, Allen B et al (2002) The acceptability of self-collected samples for HPV testing vs. the Pap test as alternatives in cervical cancer screening. J Womens Health Gend Based Med 11(3):265-275

39. Goldie SJ, Diaz M, Constenla D, Alvis N, Andrus JK, Kim SY (2008) Mathematical models of cervical cancer prevention in Latin America and the Caribbean.Vaccine 19;26 Suppl 11:L 59-72
40. Gutiérrez-Delgado C, Báez-Mendoza C, González-Pier E, de la Rosa AP, Witlen R (2008) Generalized cost-effectiveness of preventive interventions against cervical cancer in Mexican women: results of a Markov model from the public sector perspective. Salud Pub Mex 50(2):107-118 